\title{
Anti-Cancer Effects of Cordycepin on Oral Squamous Cell Carcinoma Proliferation and Apoptosis in Vitro
}

\author{
Ju-Hyon Lee ${ }^{1}$, Soon-Min Hong ${ }^{2}$, Jun-Yong Yun ${ }^{1}$, Hoon Myoung ${ }^{1 *}$, Myung-Jin Kim ${ }^{1}$ \\ ${ }^{1}$ Department of Oral \& Maxillofacial Surgery, College of Dentistry, Seoul National University, Seoul, Republic of Korea; \\ ${ }^{2}$ Department of Oral and Maxillofacial Surgery, KangDong Sacred Heart Hospital, College of Medicine, Hallym University, \\ Gangwon, Republic of Korea. \\ Email: myoungh@snu.ac.kr
}

Received January $21^{\text {st }}, 2011$; revised April $5^{\text {th }}, 2011$; accepted April 13 ${ }^{\text {th }}, 2011$.

\begin{abstract}
Cordycepin is an active component of parasitic fungus, Cordyceps militaris, and investigated for its pharmacologic efficacy. Increasing evidence supports the anti-tumoral effects of Cordycepin in various types of human solid tumors. We sought to determine the effects of Cordycepin on oral squamous cell carcinoma in vitro and in vivo. Two oral squamous cell carcinoma cell lines, KB and HSC3, were used in this study. Cells were treated with Cordycepin or diluent, followed by determinations of proliferation by sulforhodamine method and apoptosis by TUNEL assay in vitro. For in vivo experiments, tumor cells were transplanted into nude mice, followed by treatment with Cordycepin or control diluent. In addition, cells were examined for expression of adenosine receptor isotypes, and tested whether cordycepin-induced effects were mediated through adenosine receptors by combinatorial treatment of cordycepin and antagonists specific to each isotype of adenosine receptors. Two cell lines expressed protein of all types of adenosine receptors stronger than normal oral keratinocytes. Cordycepin showed anti-proliferating effect and apoptotic effect on both cell lines in vitro in a dose dependent manner. However, any adenosine receptors did not reverse the effect of cordycepin. In our in vivo experiments, cordycepin failed to decrease the tumor volume significantly, and failed to induce more apoptosis of tumor cells. Cordycepin has anti-proliferating effect and induces apoptosis not mediated by adenosine receptor on oral squamous cell carcinoma cells in vitro. However, in vivo results suggest that cordycepin in itself has a limited value as a novel chemotherapeutic agent for oral squamous cell carcinoma.
\end{abstract}

Keywords: Cordycepin, Adenosine Receptor, Oral Squamous Cell Carcinoma

\section{Introduction}

Oral squamous cell carcinoma (OSCC) shows a poor prognosis; the 5-year survival rate is only $35 \%-50 \%$ despite recent advances in radiation therapy, improvement of surgical techniques, and the advent of aggressive chemotherapy protocols [1]. Conventional cytotoxic therapies primarily target rapidly dividing cells including malignant cells as well as certain normal cells, leading to significant morbidity and limited clinical benefits of afflicted patients [2]. Therefore, it is urgently required to improve anti-cancer therapies that effectively and specifically target epithelial tumor cells while minimizing the toxic side effects on physiologically proliferating cells. In this regard, the major concern has been focused on identifying new chemotherapeutic agents with fewer side effects, and increasing attention has been paid to naturally acquired compounds for new candidates of chemotherapeutic agent.

Among naturally acquired agents explored and tested, cordycepin is a nucleoside analogue (3'-deoxyadenosine) and extracted from Cordyceps militaris that has long been used empirically as a folk medicine in Korea, Japan and China. Cordyceps militaris consists of cordycepin, nucleosides, and various polysaccharides, but most of the pharmacologic effects of Cordyceps are attributed to cordycepin [3]. Although cordycepin has been primarily used as a natural antibiotics, emerging evidence now supports multiplepharmacological effects such as 1) selective anti-bacterial effect [4];2) maturations of antigen-presenting dendritic cell (improvement of immunoregulatory function) [3]; 3) anti-fungal (Candida albi- 
cans) activity [5]; 4) anti-viral effect [6]; 5) inhibition of platelet aggregation [7]; 6) anti-inflammatory effect [8]; and 5) anti-cancer effect $[9,10]$.

Earlier studies on cordycepin focused on the anticancer effects for leukemia [10,11]. Recently, it has been found that cordycepin has inhibitory effects on solid tumors such as melanoma, epithelioid cervix carcinoma, and breast cancer cells in vitro $[10,12]$. In addition, cordycepin showed inhibitory effect on the growth of melanoma in a mouse model [13]. However, only a few studies have been performed to study the anti-cancer effect of Cordycepin on oral squamous cell carcinoma. Recently, $\mathrm{Wu}$ et al. [14] reported the pro-apoptotic effects of cordycepin on OEC-M1, a human oral squamous cancer cell line. It was demonstrated that $100 \mu \mathrm{M}$ cordycepin induced apoptosis and decreased cellular proliferation in vitro. Nevertheless, their report did not encompass in vivo data and mechanistic consideration of anti-cancer effect of cordycepin.

The biological mechanisms of anti-cancer effects of cordycepin are not completely understood yet but previous studies suggested that cordycepin effects are mediated through adenosine-adenosine receptors $[8,10]$. Adenosine is a physiological regulator of various cellular activities such as cell growth, differentiation, and cell death in wide variety of cell types [15]. There are four types of G-protein coupled surface receptors for adenosine; they are $A_{1}, A_{2 A}, A_{2 B}$, and $A_{3}$ adenosine receptors and the specific cellular response to adenosine is thought to be decided by the expression of the specific type of receptor on the cell surface [16]. Indeed, cordycepin was shown to exert anti-cancer effect through antagonizing A3 adenosine receptor $\left(A_{3} A R\right)$ [10] in melanoma and lung carcinoma. In addition, for some types of solid tumors, the mRNA expression of $\mathrm{A}_{3} \mathrm{AR}$ was verified using cell lines. Melanoma [17], prostate carcinoma [18], and some types of breast carcinoma $[19,20]$ cells expressed $\mathrm{A}_{3} \mathrm{AR}$ whereas bladder carcinoma cells [21] and some types of breast carcinoma cells $[8,19]$ did not express $\mathrm{A}_{3} \mathrm{AR}$. Gessi et al. [22] reported that the expression of $\mathrm{A}_{3} \mathrm{AR}$ protein was higher in colon carcinomas than in normal mucosa originating from the same individuals. Madi et al. [23] also verified the expression of $A_{3} A R$ in the tissues from breast and colon carcinomas patients. The results indicated that tissues from both colon and breast carcinoma expressed more $\mathrm{A}_{3} \mathrm{AR}$ mRNA and protein than those from the adjacent non-neoplastic tissue or normal tissues.

In this study, we sought to evaluate the anti-proliferating effect of cordycepin in OSCC cell lines in vitro and also in OSCC xenografted mouse tumor models in vivo. In addition, we determined whether the anti-tumoral effects of Cordycepin is mediated by specific adenosine receptors, specifically $A_{3} A R$ to obtain the rationale for further research; enhancing the therapeutic efficacy of cordycepin in OSCC.

\section{Materials and Methods}

\subsection{Cell Culture}

Two human OSCC cell lines, HSC3 (Japanese Cell Resources Bank, Osaka, Japan) and KB (American Type Culture Collection, Rockville, MD, USA), were used in this study. Cells were maintained at $37^{\circ} \mathrm{C}$ in a humidified atmosphere of $5 \% \mathrm{CO}_{2}$. In RPMI medium 1640 (Gibco, Rockville, MD, USA) supplemented with $10 \%$ fetal bovine serum (Gibco), $100 \mathrm{U} / \mathrm{ml}$ penicillin, and $100 \mu \mathrm{g} / \mathrm{ml}$ streptomycin (Gibco).

\subsection{Western Blot Analysis}

Cells were homogenized by Ultraturax (Polytron, Kinematica) in ice-cold lysis buffer [TNN buffer, $50 \mathrm{mM}$ Tris buffer ( $\mathrm{pH} 7.5$ ), $150 \mathrm{mM} \mathrm{NaCl}$, and NP40 $0.5 \%$ for 20 $\min ]$. Cell debris was removed by centrifugation for 10 minutes at 14,000 rpm. The supernatants were used for Western blot analysis. Protein concentrations were determined using the Bio-Rad protein assay dye reagent. Equal amounts of the sample $(50 \mu \mathrm{g})$ were separated by $10 \%$ SDS-PAGE. The resolved proteins were then electroblotted onto nitrocellulose membranes. Membranes were blocked with $1 \% \mathrm{BSA}$ and incubated with the desired primary antibody- $\mathrm{A}_{1} \mathrm{AR}$ (sc28995), $\mathrm{A}_{2 \mathrm{a}} \mathrm{AR}$ (sc70321), $\mathrm{A}_{2 b} \mathrm{AR}$ (sc28996), $\mathrm{A}_{3} \mathrm{AR}$ (sc7508) All antibodies were purchased (SantaCruz, Santa Cruz, CA, USA) and were used under the same reaction condition (dilution rate 1: 1000 and for 1 hour at room temperature). Blots were then washed and incubated with each type of secondary antibody for 1 hour at room temperature. Bands were recorded using ECL solution. The expression level of each receptor was measured by densitometric analysis using the BioRad scanning densitometer.

\subsection{Proliferation Assay and Morphological Analysis}

To verify the inhibitory effect of cordycepin (Sigma, St Louis, MO, USA) on the proliferation of cells, sulforhodamine B (SRB) method was used. HSC3 and KB cells $\left(1 \times 10^{5}\right.$ cells/well in 12 well plates $)$ were incubated for 24 hours. Subsequently, the cells were treated with various concentrations of cordycepin $(0 \mu \mathrm{M}, 5 \mu \mathrm{M}, 10 \mu \mathrm{M}$, $30 \mu \mathrm{M}, 50 \mu \mathrm{M}, 100 \mu \mathrm{M}, 150 \mu \mathrm{M}$, and $200 \mu \mathrm{M}$ ) for 48 hours. The cells were fixed by incubation in $50 \mu \mathrm{l}$ cold $50 \%$ TCA (trichloroacetic acid, Sigma) for 1 hour at $4^{\circ} \mathrm{C}$ in the dark. The media and TCA were removed and the plates were rinsed with water five times and then air-dried. The cells were stained by addition of $100 \mu$ of 
$0.4 \%$ sulforhodamine B (Sigma) in $1 \%$ acetic acid for 30 minutes. The stain was removed and the cells were washed five times with $1 \%$ acetic acid, air-dried, and 100 $\mu 1$ of $10 \mathrm{mM}$ unbuffered Tris was then added to each well to dissolve the dye. The plates were shaken for $5 \mathrm{~min}$ until the dye was uniformly distributed and then read on a plate reader (Molecular Devices, Sunnyvale, CA) at $540 \mathrm{~nm}$. SRB assays under various cordycepin concentrations were applied 10 times. For observation of morphologic changes of cells, KB cells and HSC 3 cells $(1 \times$ $10^{5}$ cells $/ \mathrm{ml}$ in 12 well plate) were treated with cordycepin $(0 \mu \mathrm{M}, 25 \mu \mathrm{M}, 50 \mu \mathrm{M}, 100 \mu \mathrm{M}, 200 \mu \mathrm{M}, 500 \mu \mathrm{M})$ for 48 hours. Then, cells in plates were observed under light microscope and photographed.

To confirm whether cordycepin acts via adenosine receptor, antagonist for each adenosine receptor was applied to cells with cordycepin and SRB proliferation assays were performed. The following antagonists to adenosine receptors were used: 8-cyclopentyl-1, 3-dipropylxanthine (CPX), an $\mathrm{A}_{1} \mathrm{AR}$ antagonist; 8-(3-Chlorostyryl)-caffeine, an $\mathrm{A}_{2 \mathrm{~A}} \mathrm{AR}$ antagonist; Alloxazine, an $\mathrm{A}_{2 \mathrm{~B}} \mathrm{AR}$ antagonist; 3-ethyl 5-benzyl 2-methyl-6-phenyl-4-phenylethyl-1, 4-( \pm dihydropyridine-3,5-dicarboxylate (MRS-1191), an $\mathrm{A}_{3} \mathrm{AR}$ antagonist. In this assay, $50 \mu \mathrm{M}$ of cordycepin and $1 \mu \mathrm{M}$ of each antagonist were applied to $4 \times 10^{4}$ cells in 24-well plate and cells were remained for 48 hours. This assay was repeated 10 times for each antagonist.

\subsection{Apoptosis Assay}

Apoptotic cells were detected in situ using terminal transferase dUTP nick end labeling (TUNEL) assay. HSC 3 and KB cells $\left(2 \times 10^{5}\right.$ cells/well in 6 well plate $)$ were cultured and treated with cordycepin $(50 \mu \mathrm{M})$ alone or combined with $1 \mu \mathrm{M}$ of each antagonist for 48 hours. Cells were fixed in $4 \%$ paraformaldehyde in PBS (pH 7.4) for 15 - 30 minutes at room temperature and permeabilized for 2 - 5 minutes. Subsequently, apoptotic cells were detected by the commercially available in situ apoptosis detection kit (Takara, Japan). After applying anti-FITC HRP Conjugate at $37^{\circ} \mathrm{C}$ for 30 minutes, DAB (diaminobenzidine) was applied to generate an insoluble colored substrate at the site of DNA fragmentation for 10 - 15 minutes. The DAB-labeled, fragmented DNAs were stained as dark brown indicating apoptotic cells. The apoptosis index was defined as the percentage of positive cells in 1000 cells.

\subsection{In Vivo Anti-Tumorigenesis and in Situ Apoptosis Assay}

Ten 6-week old male BALB/c nude mice (Orient Co., Suwon, Korea), weighing about $20 \mathrm{~g}$, were obtained and kept in an environment complying with the NIH guidelines for the care and use of laboratory animals. KB and
HSC 3 cells were suspended in regular culture media $(1 \times$ $10^{6}$ cells in $0.5 \mathrm{ml}$ ), and inoculated subcutaneously into the right flank of mice. Cordycepin $(30 \mathrm{mg} / \mathrm{kg})$ was administered when the volume of the ensuing mass reached $75-100 \mathrm{~mm}^{3}$ to 10 mice of each group by intraperitoneal injection for 30 days [13]. Ten mice were used as controls and only diluent (RPMI medium 1640) was injected for them. All were scarified 24 hours after the last injection of cordycepin. Each mouse was weighed every day to evaluate side effects of administrations. To evaluate tumor growth, the length and width of tumor mass were measured with a slide caliper every three days. Tumor volume (in cubic millimeters) was calculated using the following equation; Volume $\left(\mathrm{mm}^{3}\right)=$ Length $\times$ Width $^{2} \times$ $1 / 2$. The relative tumor volume (RTV) was calculated as $\mathrm{RTV}=V_{\mathrm{i}} / V_{\mathrm{o}}$, where $V_{\mathrm{i}}$ is the tumor volume at sacrifice and $V o$ is the volume at the time of initial treatment. After sacrifice, the tumors were excised, fixed in formalin, embedded in paraffin, and sectioned. Apoptosis of the cancer cells in vivo was detected using TUNEL assay with in situ apoptosis detection kit (Takara, Japan). The apoptosis index was defined as the percentage of positive cells in 1000 cells.

\subsection{Statistical Analyses}

The OD values under various cordycepin concentrations were compared with that of $0 \mu \mathrm{M}$ with Wilcoxon signed rank test. OD values of cultured cells with and without each adenosine receptor antagonist and apoptosis index were compared by Mann-Whitney $U$ test. Relative tumor volumes of control and experimental mice were also compared by Mann-Whitney $U$ test. For all analyses, $p<$ 0.05 was regarded as significant.

\section{Results}

\subsection{Expression of Adenosine Receptor}

We determined whether OSCC cells express adenosine receptors. All types of adenosine receptors were stably expressed in both OSCC cell lines. Three types of adenosine receptor were also expressed in normal oral keratinocytes but $\mathrm{A}_{2 \mathrm{~A}} \mathrm{AR}$ was not detected in normal oral gingival keratinocytes (Figure 1(a)). When the protein expressions of adenosine receptors of OSCC cell lines were compared with normal oral keratinocytes, $\mathrm{A}_{1} \mathrm{AR}, \mathrm{A}_{2 \mathrm{~B}} \mathrm{AR}$, and $A_{3} A R$ proteins were expressed significantly stronger than normal oral keratinocytes (Figure 1(b), $p<0.05$ ).

\subsection{Effects of Cordycepin and Adenosine Receptor Antagonists on Cell Proliferation in Vitro}

We determined whether cordycepin suppress proliferation of oral squamous cell carcinoma cells. After 48 hours of 


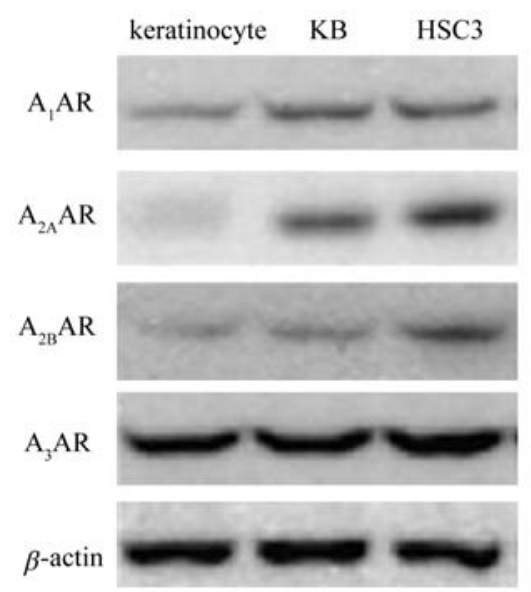

(a)

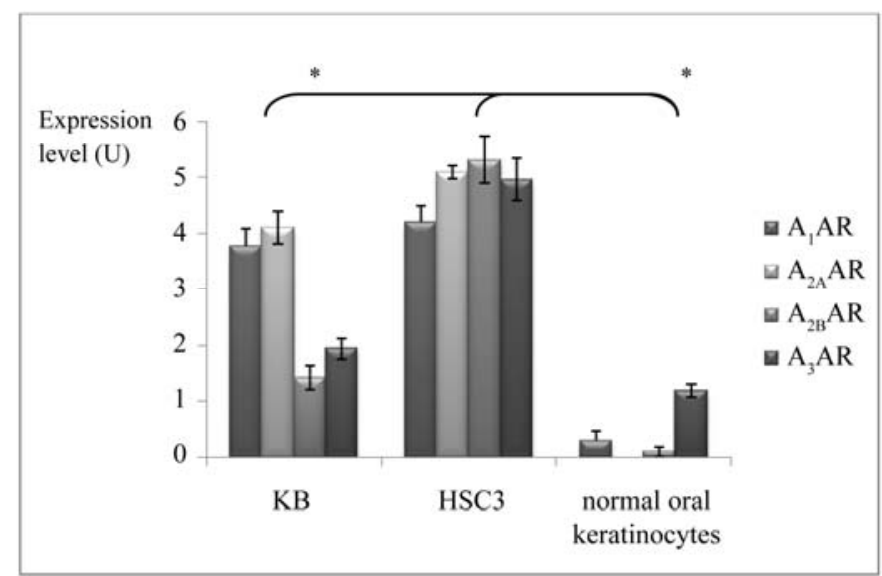

(b)

Figure 1. (a) Protein expression of adenosine receptors in normal oral keratinocytes, KB and HSC3. Four types of adenosine receptor are strongly expressed in both OSCC cells while the expressions of adenosine receptors are weaker or not expressed in normal oral keratinocytes. (b) In both OSCC cells, expression levels of $A_{1} A R, A_{2 B} A R$, and $A_{3} A R$ are stronger than each adenosine receptor of normal oral keratinocytes (*: statistically significant in mean difference of expression of each adenosine receptor between OSCC cells and normal oral keratinocytes, $p<0.05$ ).

treatment with cordycepin in various concentrations, both KB cells and HSC3 cells showed a dose-dependent decrease in the number of surviving cells (Figure 2(a)), suggesting cordycepin suppressed tumor cell proliferation. The statistically significant changes in OD values appeared from the concentration of $50 \mu \mathrm{M}$ in $\mathrm{KB}$ cell line and $30 \mu \mathrm{M}$ in HSC3 cell line $(p<0.05)$. As illustrated in Figure 2(b), morphological changes were observed in both cells treated with cordycepin $(50 \mu \mathrm{M})$. Both $\mathrm{KB}$ and HSC3 cells showed loss of their distinct morphologic characteristics and low cellular density. In addition, such a morphological change increased in a dose-dependent manner.

However, contrary to our expectation, none of adenosine receptor antagonist rescued the effects of cordycepin on tumor cell proliferation (Figure 3(a), $p>0.05$ ). In addition, morphological observation confirmed the result of proliferation assay. As shown in Figure 3(b), the shape and density of cultured cells treated with both cordycepin and one type of cordycepin receptor antagonist $\left(\mathrm{A}_{1} \mathrm{AR}, \mathrm{A}_{2 \mathrm{~A}} \mathrm{AR}, \mathrm{A}_{2 \mathrm{~B}} \mathrm{AR}\right.$, or $\mathrm{A}_{3} \mathrm{AR}$ antagonist) were not morphologically different from those of cells treated with cordycepin alone.

\subsection{Apoptosis Assay in vitro}

Under light microscope, the number of dark brown stained cells indicating apoptosis were increased in cordycepin treated group (Figures 4(a), (b), (d) and (e)). However, treatment of $1 \mu \mathrm{M}$ of adenosine receptor antagonist did not reverse cordycepin induced apoptosis in both cell lines. For example, $\mathrm{A}_{3} \mathrm{AR}$ antagonist treatment did not cause any change in both cells which had been treated with $50 \mu \mathrm{M}$ Cordycepin (Figures 4(c) and (f)).
Evaluation of apoptotic index confirmed this phenomenon statistically (Figure 4(g)). There were significant differences in apoptosis index between the control group and the Cordycepin treated group. While the apoptosis index of KB and HSC3 cells were $9.2( \pm 3.2)$ and $5.2( \pm$ 2.9) respectively, those of cells which were treated with cordycepin $(50 \mu \mathrm{M}, 48 \mathrm{~h})$ increased to $18.4( \pm 2.1)$ for $\mathrm{KB}$ and $21.8( \pm 3.5)$ for HSC3 $(p<0$.05). However, there is no significant difference in apoptosis index between the groups treated with cordycepin alone and the group treated with cordycepin and additional each type of adenosine receptor antagonist ( $p>0.05$, Figure $4(\mathrm{~g})$ ).

\subsection{Tumor Growth and Degree of Apoptosis in Vivo Model}

Next, we determined the effects of cordycepin on human OSCC implanted nude mice. The tumor volume of OSCCs in the nude mice continuously increased during whole experimental period. The relative tumor volumes (RTVs) of the KB and HSC3 tumors in the cordycepin-treated group on sacrifice were 17.6 and 8.96 respectively, which means that the tumor volume increased up to 17.6 and 8.96 times during treatment period. Meanwhile, the RTVs of KB and HSC3 tumors in the control group were 18.4 and 9.20 at sacrifice (Figure 5(a)(b)). However, no significant difference was found between the experimental group and the control group in tumor volume change $(p>0.05)$. Histological observation of the tumor showed that there was no difference in the degree of in situ apoptosis (stained as dark brown) between the experimental group which was administered with cordycepin $(30 \mathrm{mg} / \mathrm{kg}, 14$ days) and the control 

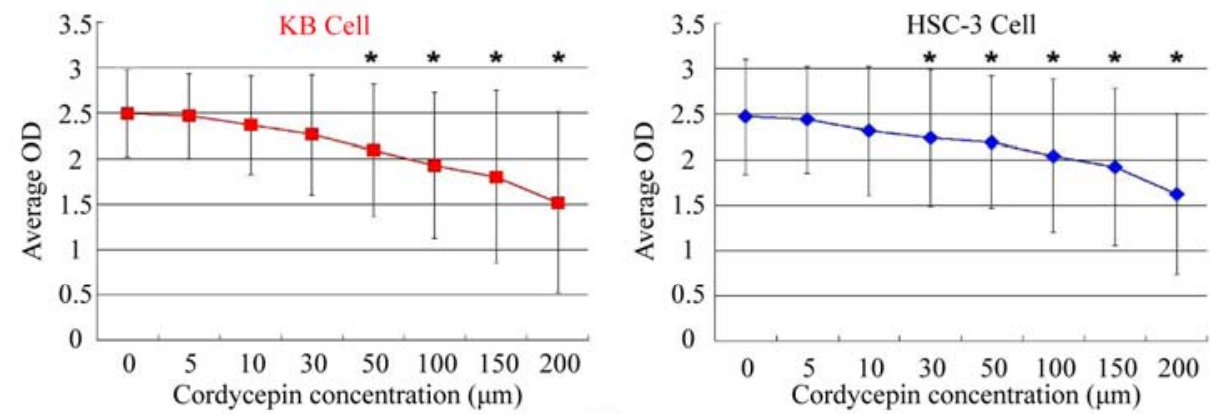

(a)

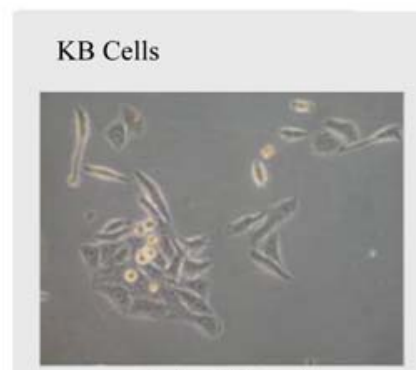

Control $(0 \mu \mathrm{m})$

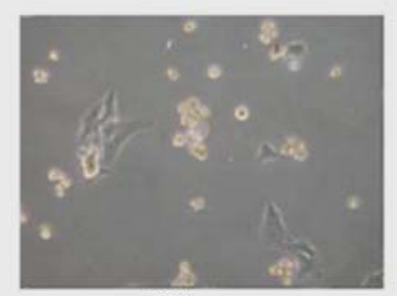

$100 \mu \mathrm{m}$

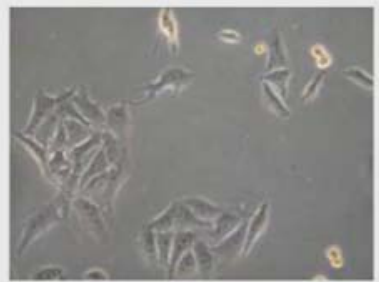

$25 \mu \mathrm{m}$

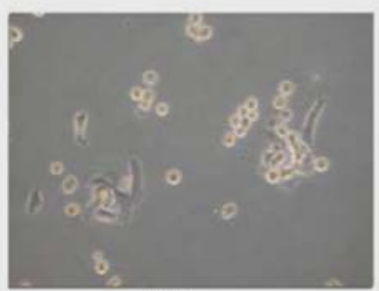

$200 \mu \mathrm{m}$

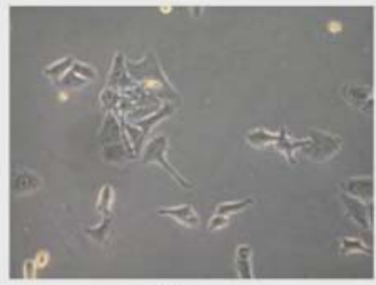

$50 \mu \mathrm{m}$

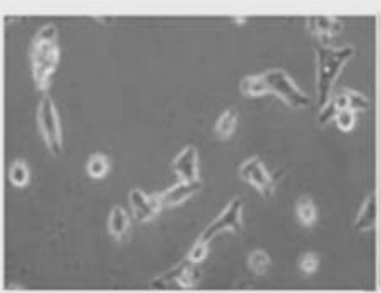

$500 \mu \mathrm{m}$

\section{HSC-3 Cells}

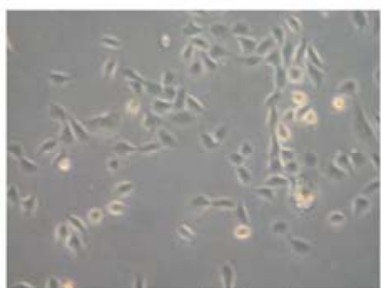

Control $(0 \mu \mathrm{m})$

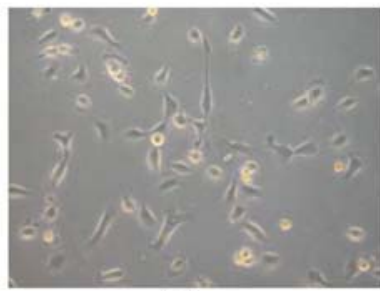

$100 \mu \mathrm{m}$

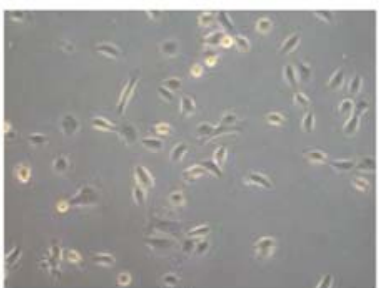

$25 \mu \mathrm{m}$

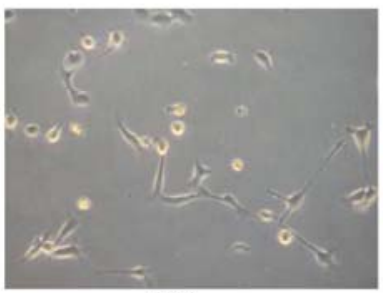

$200 \mu \mathrm{m}$

(b)

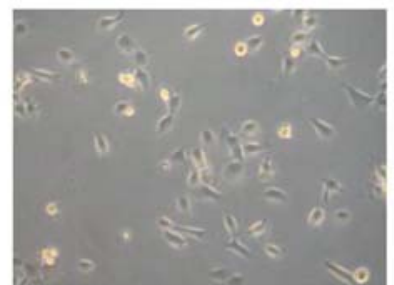

$50 \mu \mathrm{m}$

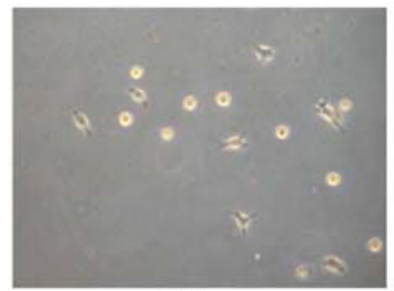

$500 \mu \mathrm{m}$

Figure 2. (a) Proliferation (OD) of KB and HSC-3 cells under various concentrations of cordycepin for 48 hours. Both cells show decreases in proliferation in a dose-dependent manner. Statistically significant decreases $(*)$ appear from $50 \mu M$ in KB cells and $30 \mu \mathrm{M}$ in HSC3 cells. (b) Morphological changes in KB and HSC3 cells treated with cordycepin are observed under the light microscope and photographed. As concentration of cordycepin is higher, cells become pleomorphic in shape and show low cellular density (magnification, $\times 100)$. 

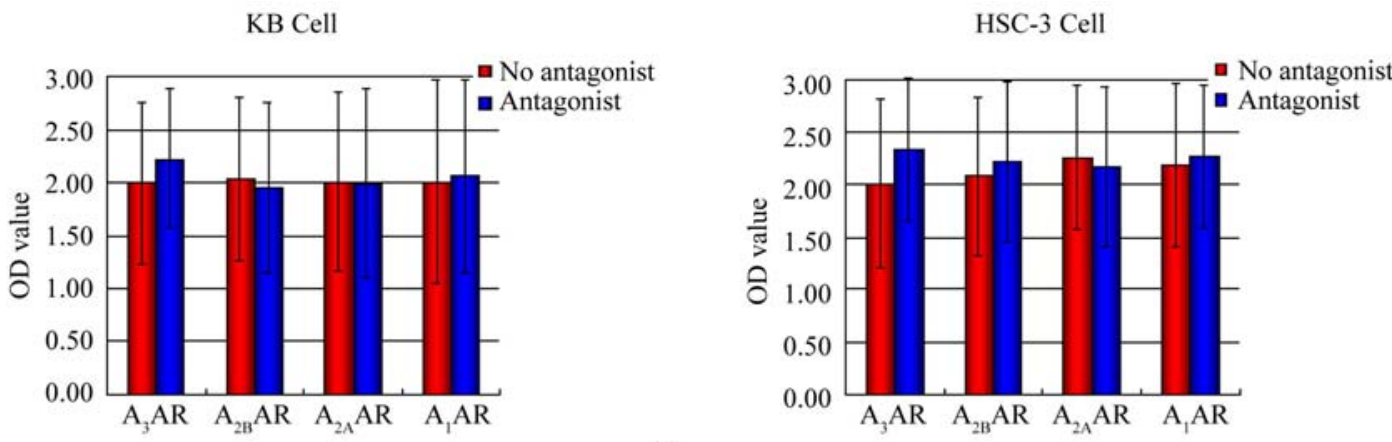

(a)
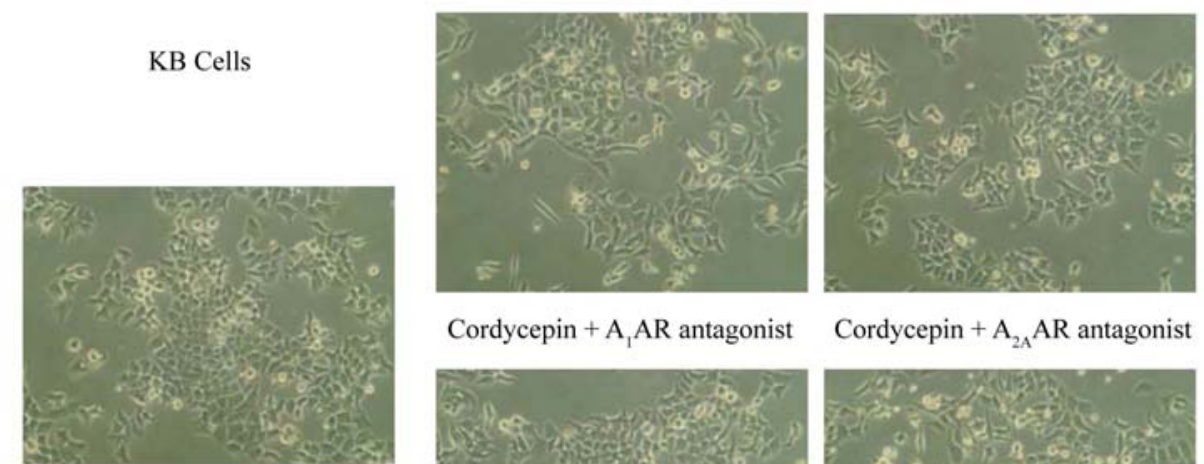

Cordycepin $+\mathrm{A}_{1} \mathrm{AR}$ antagonist

Cordycepin $+\mathrm{A}_{2 \mathrm{~A}} \mathrm{AR}$ antagonist
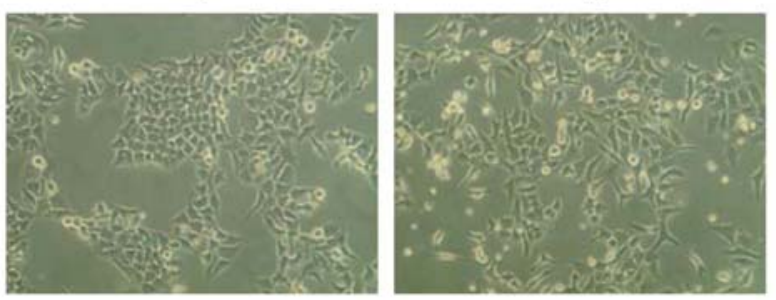

Cordycepin $+\mathrm{A}_{2 \mathrm{~B}} \mathrm{AR}$ antagonist

Cordycepin $+\mathrm{A}_{3} \mathrm{AR}$ antagonist

HSC-3 Cells
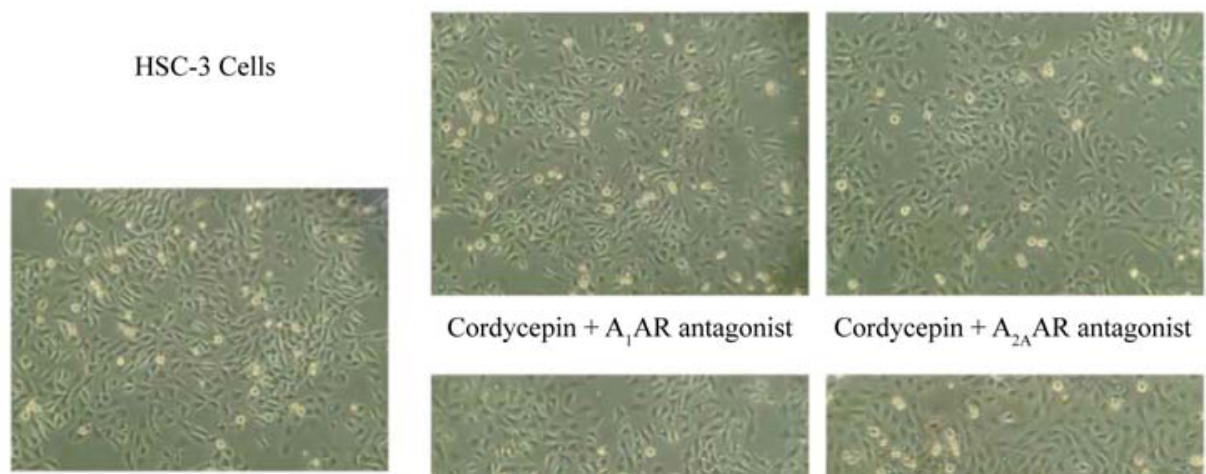

Cordycepin $+\mathrm{A}_{1} \mathrm{AR}$ antagonist

Cordycepin $+\mathrm{A}_{2 \mathrm{~A}} \mathrm{AR}$ antagonist

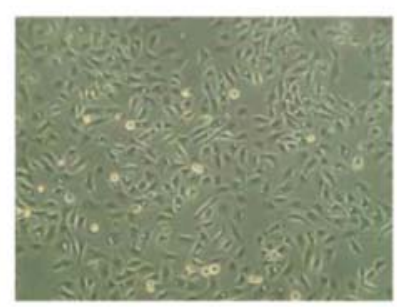

Cordycepin $+\mathrm{A}_{2 \mathrm{~B}} \mathrm{AR}$ antagonist

(b)

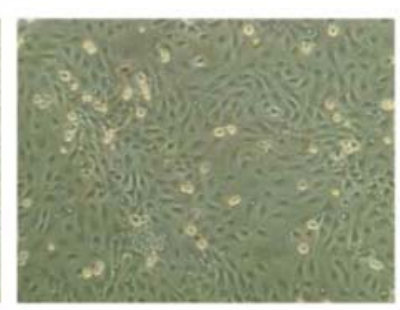

Cordycepin $+\mathrm{A}_{3} \mathrm{AR}$ antagonist

Figure 3. (a) Effect of adenosine receptor antagonists on the anti-proliferating effect of cordycepin. No adenosine receptor antagonist reverses the anti-proliferating effect of cordycepin. (b) Morphological changes in KB and HSC3 cells treated with cordycepin $(50 \mu \mathrm{M})$ alone or cordycepin with each adenosine receptor antagonist $(1 \mu \mathrm{M})$ for 48 hours. In each cell line treated with cordycepin, the addition of each adenosine receptor could not induce significant reversal of cellular density or cell morphology (magnification, $\times$ 40). 


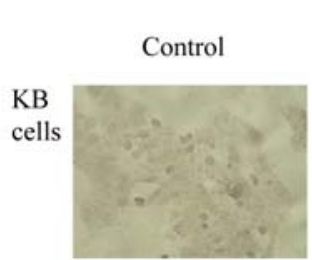

(a)

HSC3 cells

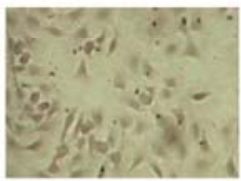

(d)

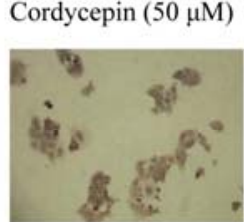

(b)

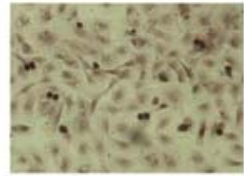

(e)
Cordycepin with

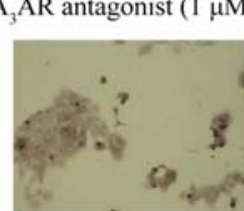

(c)

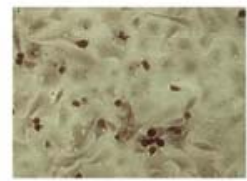

(f)

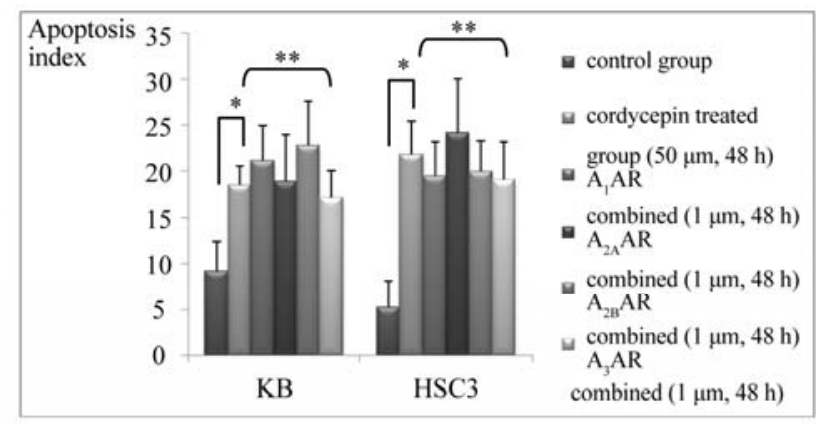

(g)

Figure 4. Apoptosis assays on KB cells and HSC3 cells. Cordycepin induced apoptosis in both OSCC cell lines and apoptotic cells are represented as dark brown stain. Note more apoptotic bodies are observed in cordycepin treated KB (b) and HSC3 (e) cells than in respective control cells (a and d, magnification $\times 100)$. Meanwhile, cordycepin induced apoptosis are not morphologically reversed by adenosine receptor antagonist $\left(A_{3} A R\right.$ in this figure) treatment in KB (c) and HSC3 (f). Apoptosis index (g) demonstrates that there is a significant difference in apoptosis between the cordycepin treated group and the control group $(*, p<0.05)$ while no significance is detected in apoptosis index between the group of cordycepin treatment alone and the each group of adenosine receptor antagonist combined with cordycepin $(* *, p>0.05)$.

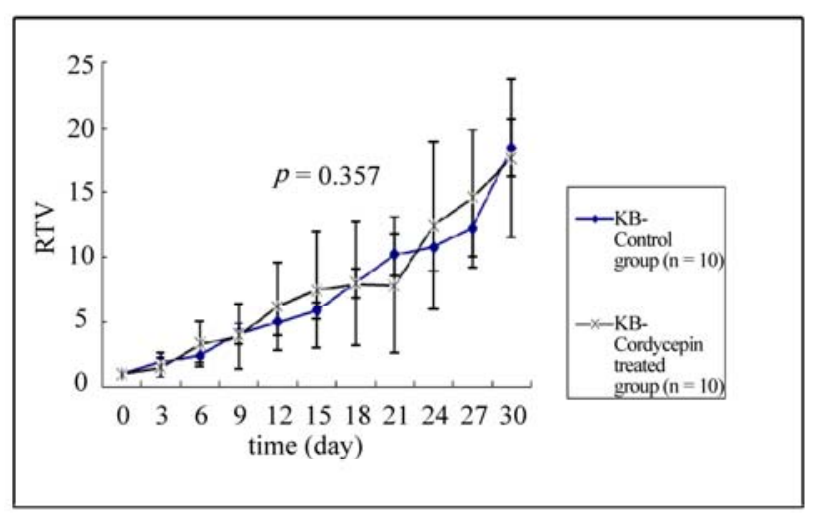

(a)

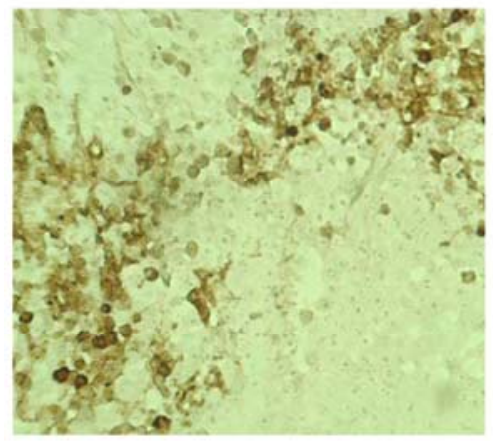

(c)

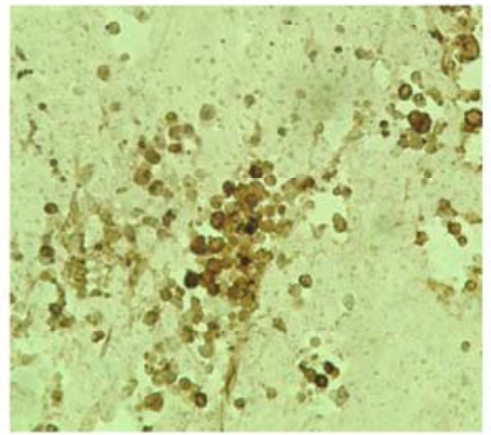

(d)

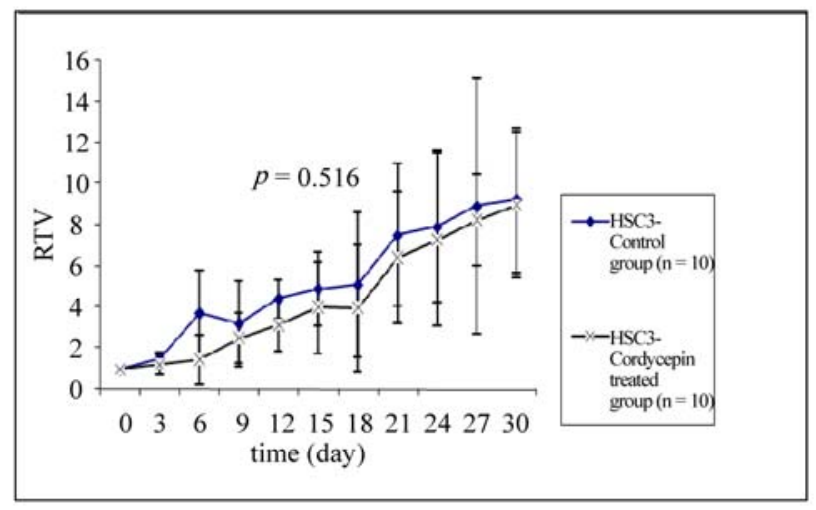

(b)

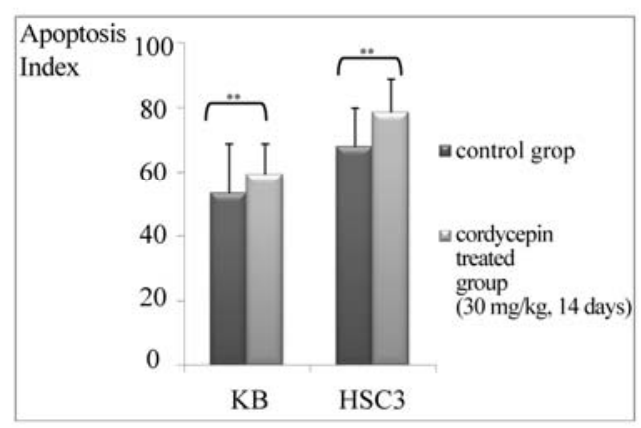

(e)

Figure 5. Tumorigenesis assay and in situ apoptosis assays on tissues obtained from the xenografted mice. Relative tumor volume (RTV) increased through experimental period in KB (a) and HSC3 (b). Note that RTV of the cordycepin treated group is lower than that of the control group in some experimental period, but is not statistically significant $(p>0.05)$ There is no difference in the density of apoptotic cell and histo-morphological characteristics between control mice (c) and cordycepin treated mice (d) (apoptotic cell stained as dark brown, magnification, $\times 100)$. (e) Apoptotic index is not significantly different between in the control (injection of diluent) and the experimental (30 mg/kg of cordycepin) groups (**: $p>0.05)$. 
(administration of diluent only) group (Figures 5(c) and (d)). While the apoptosis index of KB and HSC3 cells were $53.2( \pm 15.4)$ and $67.9( \pm 11.9)$ respectively, those of cordycepin treated cells increased to $59.2( \pm 9.4)$ for $\mathrm{KB}$ and $78.3( \pm 10.3)$ for HSC3. Difference of apoptotic index was not statistically significant between the control group and the experimental group (Figure 5(e); $p<$ $0.05)$.

\section{Discussion}

In the present study, the results of in vitro anti-proliferating assay showed significant and dose dependent anti-proliferating activity of cordycepin on OSCC. The statistically significant decreases of the cellular proliferation appeared from the concentration of $50 \mu \mathrm{M}$ in $\mathrm{KB}$ cell and $30 \mu \mathrm{M}$ in HSC3 cell. The inhibitory concentrations of this study were much lower than those of Wu's study ${ }^{14}$ but inhibitory effect was weaker than those of melanoma case. Cordycepin at $100 \mu \mathrm{M}$ for 48 hours could reduce the cell number of mouse melanoma cell (B16-BL6) by $83 \%$ [10] whereas OD values of KB cells and HSC3 cells decreased only $21.7 \%$ and $17.32 \%$ in this study. Even though the major advantage of cordycepin is its wide safety margin, relatively weaker anti-proliferating activity of cordycepin may be a definite limitation in practical application of cordycepin as a novel chemotherapeutic drug. Thus, it is recommended that further studies to enhance anti-proliferating activity of cordycepin are needed.

Among four types of adenosine receptor, $\mathrm{A}_{3} \mathrm{AR}$ and inhibitory effect of its agonist on many cancer cell types were mainly inspected and it is now generally accepted that $\mathrm{A}_{3} \mathrm{AR}$ agonists exert their anti-cancer effects on solid tumors, such as melanoma, breast carcinoma, prostate carcinoma, and colon carcinoma [8,18,19,24-26]. Accordingly, cordycepin has been also studied based on the relationship with $\mathrm{A}_{3} \mathrm{AR}$. Recently, Nakamura et al. ${ }^{10}$ revealed the structural similarity between adenosine and cordycepin and they tested cordycepin as an $\mathrm{A}_{3} \mathrm{AR}$ agonist. According to their in vitro experiment, the inhibitory effect of cordycepin on tumor growth was exclusively antagonized by only a selective $\mathrm{A}_{3} \mathrm{AR}$ antagonist among all adenosine receptor antagonists. With this result, they concluded that cordycepin exerts inhibitory effects on the growth of mouse melanoma and lung carcinoma cells by stimulating $\mathrm{A}_{3} \mathrm{AR}$ on tumor cells. Moreover, the concentration of $A_{3} A R$ agonist is thought to be a major factor to determine the inhibitory mechanism in case of lymphoma and leukemia [27,28]. However, in solid tumors, the existence or expression level of $\mathrm{A}_{3} \mathrm{AR}$ is also thought be an additional important factor because $A_{3} A R$ is not expressed consistently in all types of solid tumors [8]. In an attempt to reveal the relation- ships with adenosine receptor in OSCC, we evaluated the expression of all types of adenosine receptor using OSCC cell lines. Our Western blotting data clearly demonstrated that two tested cell lines, KB and HSC3 showed stronger expression of all types of adenosine receptors than primary cultured oral gingival keratinocytes. From these results, adenosine-adenosine receptor mechanism was also thought be a critical tumorigenic process in case of OSCC. However, when each adenosine receptor antagonist was applied to cordycepin treated cancer cells in the current study, none of adenosine receptor antagonists significantly reversed the anti-proliferating effect of cordycepin on OSCC cell. These results could be reconfirmed by observing cancer cells with light microscope. Thus, we concluded that cordycepin seemed to have anti-proliferating effect not mediated by any type of adenosine receptor in OSCC cell lines despite strong expression of all types of adenosine receptors.

It is reported that $A_{3} A R$ agonists exert inhibitory effects on cancer cells through two different mechanisms; cytostatic effect (cell-cycle arresting) via $\mathrm{A}_{3} \mathrm{AR}$ and cytotoxic effect (induction of apoptosis) via active transport $[16,29]$. $A_{3} A R$ agonists, at low concentration, resulted in cell cycle arrest but at high concentration, induced apoptosis of melanoma and leukemia cells [16,29]. Likewise, induction of apoptosis has been proposed as another mechanism of cordycepin for suppression of cancer cells [16]. Evidences showed apoptosis could be induced in cancer cells that do not have $\mathrm{A}_{3} \mathrm{AR}$ and this means that induction of apoptosis may not be directly mediated by $\mathrm{A}_{3} \mathrm{AR}[8,30,31]$. This is evidenced by the facts that apoptosis of cells by $\mathrm{A}_{3} \mathrm{AR}$ agonists was not reversed by $\mathrm{A}_{3} \mathrm{AR}$ antagonists [32] but antagonized by the addition of adenosine transporter protein [30,31]. Thus, cancer cells that do not have $\mathrm{A}_{3} \mathrm{AR}$ or not respond to $\mathrm{A}_{3} \mathrm{AR}$ activation may be inhibited by cordycepin at higher concentration via induction of apoptosis. In our in vitro apoptosis assay demonstrated that the apoptosis index of both OSCC cell lines significantly increased by $50 \mu \mathrm{M}$ of cordycepin, and apoptotic process was not reversed by adenosine receptor antagonist in both cell lines. In addition to the proliferation assay, these results confirmed that OSCC did not respond to adenosine receptor activation and suggested that anti-cancer effect of cordycepin may be mediated by induction of apoptosis. Thus, previous studies and the results of current study support that inducing apoptosis of OSCC cells is mediated by active transport, independent of adenosine receptor.

Although in vitro results of the current study showed that cordycepin exhibits effective anti-cancer activity via direct cellular apoptotic effect, a critical question about the practical value of cordycepin as a main anti-cancer 
agent for OSCC was raised because cordycepin treatment failed to inhibit tumor growth in vivo OSCC model in the present study. In a report, administration of cordycepin (15 mg/kg per day) for 2 weeks inhibited the tumor enlargement inoculated with mouse melanoma (B16-BL6) cells in mice [13]. However, in our study, even cordycepin administration of higher concentration $(30 \mathrm{mg} / \mathrm{kg}$ per day for 4 weeks) could not suppress OSCC growth significantly in two types of xenotransplanted nude mice model. The tumor mass generated by inoculation with $\mathrm{KB}$ or HSC3 cells grew without any reduction in mass size throughout the experimental period. Moreover, in situ apoptosis assay showed that there was no difference of apoptotic index between the experimental group animals and the control group animals. We originally expected based on in vitro experiment that, at the very least, tumor mass growth of the tumor would be retarded with increased apoptosis. However, there was no evidence of growth inhibition of tumor mass and no increased apoptosis following cordycepin administration. The results of this preliminary in vivo study suggest some possibilities as followed, although more advanced experimental analyses should be performed in further study to prove them. First, originally sensitive OSCC cells in vitro state gained resistance against cordycepin by altering genetic characteristics during tumorigenic process. The second possibility is that plasma levels of cordycepin could not be achieved enough to induce direct apoptosis by presented administration method. Considering that in vitro study showed that anti-cancer effect of cordycepin on OSCC cells was not mediated with adenosine receptor activation but dependent on direct induction of apoptosis, higher concentration and longer application time of cordycepin might be a prerequisite for induction of apoptosis $[29,32]$. Therefore, pharmacokinetic evaluation and blood concentration monitoring of cordycepin will be needed in further study. In summary, this study highlighted the possibility of Cordycepin as a safe and a natural anti-cancer agent against OSCC in vitro but, there's definite limitation to be used as sole anti-cancer drug in vivo.

\section{Acknowledgements}

"This research was supported by Basic Science Research Program through the National Research Foundation of Korea (NRF) funded by the Ministry of Education, Science and Technology (2010-0016443). Ju-Hyon Lee and Soon-Min Hong gave equal contribution on this paper as 1st author."

\section{REFERENCES}

[1] D. M. Parkin, F. Bray, J. Ferlay and P. Pisani, "Global Cancer Statistics 2002," CA: A Cancer Journal for Clini- cians, Vol. 55, No. 2, March/April 2005, pp. 74-108. doi:10.3322/canjclin.55.2.74

[2] E. S. Kim, M. Kies and R. S. Herbst, "Novel Therapeutics for Head and Neck Cancer," Current Opinion in Oncology, Vol. 14, No. 3, May 2002, pp. 334-342. doi:10.1097/00001622-200205000-00014

[3] G. Y. Kim, W. S. Ko, J. Y. Lee, J. O. Lee, C. H. Ryu, B. T. Choi, Y. M. Park, Y. K. Jeong, K. J. Lee, K. S. Choi, M. S. Heo and Y. H. Choi, "Water Extract of Cordyceps Militaris Enhances Maturation of Murine Bone Marrow-Derived Dendritic Cells in Vitro," Biological \& Pharmaceutical Bulletin, Vol. 29, No. 2, February 2006, pp. 354-360. doi:10.1248/bpb.29.354

[4] M. E. Rottenberg, W. Masocha, M. Ferella, F. Petitto-Assis, H. Goto, K. Kristensson, R. McCaffrey and H. Wigzell, "Treatment of African Trypanosomiasis with Cordycepin and Adenosine Deaminase Inhibitors in a Mouse Model," Journal of Infectious Diseases, Vol. 192, No. 9, November 2005, pp. 1658-1665. doi:10.1086/496896

[5] A. M. Sugar and R. P. McCaffrey, "Antifungal Activity of 3'-Deoxyadenosine (Cordycepin)," Antimicrobial Agents and Chemotherapy, Vol. 42, No. 6, June 1998, pp. 1424-1427.

[6] F. L. Xu, Y. L. Lee, W. Y. Tsai, S. J. Lin, Z. Q. Yang, C. C. Yang, H. Y. Liu, L. Cheng, H. Xiao and L. Wen, "Effect of Cordycepin on Hantaan Virus 76-118 Infection of Primary Human Embryonic Pulmonary FibroblastsCharacterization of Apoptotic Effects," Acta Virologica, Vol. 49, No. 3, 2005, pp. 183-193.

[7] H. J. Cho, J. Y. Cho, M. H. Rhee and H. J. Park, "Cordycepin (3'-deoxyadenosine) Inhibits Human Platelet Aggregation in a Cyclic AMP- and Cyclic GMP-Dependent Manner," European Journal of Pharmacology, Vol. 558, No. 1-3, 8 March 2007, pp. 43-51.

doi:10.1016/j.ejphar.2006.11.073

[8] H. Chung, J. Y. Jung, S. D. Cho, K. A. Hong, H. J. Kim, D. H. Shin, H. Kim, H. O. Kim, D. H. Shin, H. W. Lee, L. S. Jeong and G. Kong, "The Antitumor Effect of LJ-529, a Novel Agonist to A3 Adenosine Receptor, in both Estrogen Receptor-Positive and Estrogen Receptor-Negative Human Breast Cancers," Molecular Cancer Therapeutics, Vol. 5, No. 3, March 2006, pp. 685-692. doi:10.1158/1535-7163.MCT-05-0245

[9] Y. Koc, A. G. Urbano, E. B. Sweeney and R. McCaffrey, "Induction of Apoptosis by Cordycepin in ADA-Inhibited TdT-Positive Leukemia Cells," Leukemia, Vol. 10, No. 6, June 1996, pp. 1019-1024.

[10] K. Nakamura, N. Yoshikawa, Y. Yamaguchi, S. Kagota, K. Shinozuka and M. Kunitomo, "Antitumor Effect of Cordycepin (3'-deoxyadenosine) on Mouse Melanoma and Lung Carcinoma Cells Involves Adenosine A3 Receptor Stimulation," Anticancer Research, Vol. 26, No.1A, January/February 2006, pp. 43-47.

[11] F. M. Foss, "Combination Therapy with Purine Nucleoside Analogs," Oncology (Williston Park), Vol. 14, No. 6, Supplement 2, June 2000, pp. 31-35. 
[12] H. Thomadaki, C. M. Tsiapalis and A. Scorilas, "Polyadenylate Polymerase Modulations in Human Epithelioid Cervix and Breast Cancer Cell Lines, Treated with Etoposide or Cordycepin, Follow Cell Cycle rather than Apoptosis Induction," Biological Chemistry, Vol. 386, No. 5, May 2005, pp. 471-480. doi:10.1515/BC.2005.056

[13] N. Yoshikawa, K. Nakamura, Y. Yamaguchi, S. Kagota, K. Shinozuka and M. Kunitomo, "Antitumour Activity of Cordycepin in Mice," Clinical and Experimental Pharmacology and Physiology, Vol. 31, No. Supplement 2, December 2004, pp. S51-53.

[14] W. C. Wu, J. R. Hsiao, Y. Y. Lian, C. Y. Lin and B. M. Huang, "The Apoptotic Effect of Cordycepin on Human OEC-M1 Oral Cancer Cell Line," Cancer Chemotherapy and Pharmacology, Vol. 60, No. 1, June 2007, pp. 103-111. doi:10.1007/s00280-006-0354-y

[15] A. J. Nordone and E. B. Pivorun, "Cytosolic Calcium Responses to Extracellular Adenosine 5',5" '-P1,P4-Tetraphosphate in PC12 Cells," Pharmacology Biochemistry and Behavior, Vol. 52, No. 1, September 1995, pp. 85-91. doi:10.1016/0091-3057(95)00018-R

[16] G. Ohana, S. Bar-Yehuda, F. Barer and P. Fishman, "Differential Effect of Adenosine on Tumor and Normal Cell Growth: Focus on the A3 Adenosine Receptor," Journal of Cellular Physiology, Vol. 186, No. 1, January 2001, pp. 19-23. doi:10.1002/1097-4652(200101)186:1<19::AID-JCP1011 $\geq 3.0 . \mathrm{CO} ; 2-3$

[17] S. Merighi, K. Varani, S. Gessi, E. Cattabriga, V. Iannotta, C. Ulouglu, E. Leung and P. A. Borea, "Pharmacological and Biochemical Characterization of Adenosine Receptors in the Human Malignant Melanoma A375 Cell Line," British Journal of Pharmacology, Vol. 134, No. 6, November 2001, pp. 1215-1226. doi:10.1038/sj.bjp.0704352

[18] P. Fishman, S. Bar-Yehuda, E. Ardon, L. Rath-Wolfson, F. Barrer, A. Ochaion and L. Madi, "Targeting the A3 Adenosine Receptor for Cancer Therapy: Inhibition of Prostate Carcinoma Cell Growth by A3AR Agonist," Anticancer Research, Vol. 23, No. 3A, May/June 2003, pp. 2077-2083.

[19] J. Lu, A. Pierron and K. Ravid, "An Adenosine Analogue, IB-MECA, Down-Regulates Estrogen Receptor Alpha and Suppresses Human Breast Cancer Cell Proliferation," Cancer Research, Vol. 63, No. 19, 1 October 2003, pp. 64136423.

[20] M. Panjehpour and F. Karami-Tehrani, "An Adenosine Analog (IB-MECA) Inhibits Anchorage-Dependent Cell Growth of Various Human Breast Cancer Cell Lines," International Journal of Biochemistry \& Cell Biology, Vol. 36, No. 8, August 2004, pp. 1502-1509. doi:10.1016/j.biocel.2003.12.001

[21] P. T. Phelps, J. C. Anthes and C. Correll, "Characterization of Adenosine Receptors in the Human Bladder Carcinoma T24 Cell Line," European Journal of Pharmacology, Vol. 536, No. 1-2, April 2006, pp. 28-37. doi:10.1016/j.ejphar.2006.02.046

[22] S. Gessi, E. Cattabriga, A. Avitabile, R. Gafa, G. Lanza, L. Cavazzini, N. Bianchi, R. Gambari, C. Feo, A. Liboni,
S. Gullini, E. Leung, S. Mac-Lennan and P. A. Borea, "Elevated Expression of A3 Adenosine Receptors in Human Colorectal Cancer is Reflected in Peripheral Blood Cells," Clinical Cancer Research, Vol. 10, No. 17, 1 September 2004, pp. 5895-5901. doi:10.1158/1078-0432.CCR-1134-03

[23] L. Madi, A. Ochaion, L. Rath-Wolfson, S. Bar-Yehuda, A. Erlanger, G. Ohana, A. Harish, O. Merimski, F. Barer and P. Fishman, "The A3 Adenosine Receptor is Highly Expressed in Tumor Versus Normal Cells: Potential Target for Tumor Growth Inhibition," Clinical Cancer Research, Vol. 10, No. 13, 1 July 2004, pp. 4472-4479.

doi:10.1158/1078-0432.CCR-03-0651

[24] P. Fishman, S. Bar-Yehuda, F. Barer, L. Madi, A. S. Multani and S. Pathak, "The A3 Adenosine Receptor as a New Target for Cancer Therapy and Chemoprotection," Experimental Cell Research, Vol. 269, No. 2, October 2001, pp. 230-236. doi:10.1006/excr.2001.5327

[25] P. Fishman, S. Bar-Yehuda, G. Ohana, F. Barer, A. Ochaion, A. Erlanger and L. Madi, "An Agonist to the A3 Adenosine Receptor Inhibits Colon Carcinoma Growth in Mice via Modulation of GSK-3 Beta and NF-kappa B," Oncogene, Vol. 23, No. 14, 1 April 2004, pp. 2465-2471. doi:10.1038/sj.onc.1207355

[26] P. Fishman, L. Madi, S. Bar-Yehuda, F. Barer, L. Del Valle and K. Khalili, "Evidence for Involvement of Wnt Signaling Pathway in IB-MECA Mediated Suppression of Melanoma Cells," Oncogene, Vol. 21, No. 25, June 2002, pp. 4060-4064. doi:10.1038/sj.onc. 1205531

[27] Y. Kohno, Y. Sei, M. Koshiba, H. O. Kim and K. A. Jacobson, "Induction of Apoptosis in HL-60 Human Promyelocytic Leukemia Cells by Adenosine A(3) Receptor Agonists," Biochemical and Biophysical Research Communications, Vol. 219, No. 3, February 1996, pp. 904-910. doi:10.1006/bbrc.1996.0331

[28] Y. Yao, Y. Sei, M. P. Abbracchio, J. L. Jiang, Y. C. Kim and K. A. Jacobson, "Adenosine A3 Receptor Agonists Protect HL-60 and U-937 Cells from Apoptosis Induced by A3 Antagonists," Biochemical and Biophysical Research Communications, Vol. 232, No. 2, March 1997, pp. 317-322. doi:10.1006/bbrc.1997.6290

[29] E. J. Lee, H. Y. Min, H. J. Chung, E. J. Park, D. H. Shin, L. S. Jeong and S. K. Lee, "A Novel Adenosine Analog, Thio-Cl-IB-MECA, Induces G0/G1 Cell Cycle Arrest and Apoptosis in Human Promyelocytic Leukemia HL-60 Cells," Biochemical Pharmacology, Vol. 70, No. 6, September 2005, pp. 918-924.

[30] C. Schneider, H. Wiendl and A. Ogilvie, "Biphasic Cytotoxic Mechanism of Extracellular ATP on U-937 Human Histiocytic Leukemia Cells: Involvement of Adenosine Generation," Biochemica et Biophysica Acta (BBA)-Molecular Cell Research, Vol. 1538, No. 2-3, April 2001, pp. 190-205.

[31] L. F. Wu, G. P. Li, J. L. Feng and Z. J. Pu, "Molecular Mechanisms of Adenosine-Induced Apoptosis in Human HepG2 Cells," Acta Pharmacologica Sinica, Vol. 27, No. 4, April 2006, pp. 477-484. doi:10.1111/j.1745-7254.2006.00302.x 
[32] S. G. Kim, G. Ravi, C. Hoffmann, Y. J. Jung, M. Kim, A. Chen and K. A. Jacobson, "P53-Independent Induction of Fas and Apoptosis in Leukemic Cells by an Adenosine
Derivative, Cl-IB-MECA," Biochemical Pharmacology, Vol. 63, No. 5, March 2002, pp. 871-80.

doi:10.1016/S0006-2952(02)00839-0 